\title{
Núcleo de Tecnologia Digital Aplicada à Educação (NUTED)
}

\author{
Patricia A. Behar ${ }^{1}$, Magalí T. Longhi², Ariane N. C. Longaray ${ }^{1}$ \\ ${ }^{1}$ Faculdade de Educação - Universidade Federal do Rio Grande do Sul (UFRGS) \\ Caixa Postal - 90046-900 - Porto Alegre - RS - Brasil \\ ${ }^{2}$ Centro de Processamento de Dados - Universidade Federal do Rio Grande do Sul \\ (UFRGS) - Porto Alegre - RS - Brasil \\ pbehar@terra.com.br, magali@cpd.ufrgs.br, arianenichele@gmail.com
}

O NUTED trabalha com o desenvolvimento e a utilização de tecnologias digitais aplicadas à educação. Trata-se de um grupo interdisciplinar constituído por três equipes: pedagógica, de programadores e designers, auxiliando pesquisadores em Educação Fundamental e Básica, Educação Superior, Profissional, Educação de Idosos e Educação a Distância, com aplicação em escolas e cursos de graduação, pós-graduação e extensão da UFRGS. O Núcleo tem como objetivo, prover inovações em ambientes virtuais de aprendizagem, de forma que eles sirvam de suporte ao Ensino Presencial e à Educação a Distância. O NUTED possui como principais projetos os seguintes temas: (1) Modelos Pedagógicos em Educação a Distância: das tecnologias às competências. Desenvolvimento de modelos pedagógicos em educação a distância, focalizando a construção de tecnologias associada à discussão sobre as competências de professores, alunos e tutores para incorporarem os novos recursos educacionais e ambientes virtuais de aprendizagem. Òrgão de fomento: $\mathrm{CNPq}(2) ;$ ROODA - Rede cOOperativa De Aprendizagem. É uma plataforma de EAD, que oferece aos docentes a possibilidade de estruturarem, com suporte em ferramentas síncronas e assíncronas, suas propostas pedagógicas. Vem sendo utilizada desde 2005, em cursos presenciais e a distância de graduação, pós-graduação e extensão da UFRGS. Órgãos de fomento: CNPQ e SEAD/UFRGS; (3) Planeta ROODA. É um ambiente virtual de aprendizagem que tem como objetivo desenvolver o trabalho coletivo na internet com alunos $\mathrm{e}$ professores da Educação Fundamental e Básica. Órgãos de fomento: $\mathrm{CNPq}$ e FAPERGS; (4) Editor de Texto Coletivo (ETC). É um espaço virtual para a construção coletiva de textos a distância. Segue os princípios da Web 2.0 e agrega recursos de mineração de texto. Órgão de fomento: CAPES

Coordenadora - Patricia Alejandra Behar; Pesquisadores/Desenvolvedores Alexandra L. Macedo; Alexandre Leuck; Ana Carolina R. Ribeiro; André A. da Cunha; Ariane N. C. Longaray; Caroline B. do Amaral; Clarissa Holz; Cláudia Zank; Daisy Schneider; Fátima W. Rosas; João V. Albertoni; Ketia K. A. da Silva; Larissa Ebeling; Leticia R. Machado; Luiz A. Risso; Magalí T. Longhi; Maira Bernardi; Natália Reisdorfer; Rodrigo F. Leite; Sabrina E.A da Luz; Sandra A. A. Maria; Sibele P. Loss; Silvia F. S.Moresco; Tássia P. F. Grande; Yuri P. Gossmann. 